\title{
Depression, Anxiety, Related Risk Factors and Cognitive Distortion in Korean Patients with Inflammatory Bowel Disease
}

\author{
Jun Ho Song ${ }^{1}$, Jong Woo Kim¹, Chi Hyuk Oh², Hyo Jong Kim², Chang Kyun Lee ${ }^{2 凶}$, and Won Sub Kang ${ }^{1}$ \\ 'Department of Psychiatry, Kyung Hee University College of Medicine, Seoul, Republic of Korea \\ ${ }^{2}$ Center for Crohn's and Colitis, Department of Gastroenterology, Kyung Hee University College of Medicine, Seoul, Republic of Korea
}

Objective To evaluate the severity of depression, anxiety, associated risk factors, and cognitive distortion in Korean patients with ulcerative colitis (UC) and Crohn's disease (CD).

Methods This study included 369 patients with inflammatory bowel disease. The severity of depression and anxiety was examined using Patient Health Questionnaire-9 and Hospital Anxiety and Depression Scale. The Anxious Thoughts and Tendencies scale was used to measure catastrophizing tendency. Multivariate regression analyses were performed.

Results The predictors of depression were marital status, anti-tumor necrosis factor- $\alpha$ (TNF- $\alpha$ ) agent use, age, and body mass index in UC patients and marital status, disease activity, alcohol use, and employment status in CD patients. For anxiety, sex and marital status were the associated factors in UC patients, whereas steroid use was the only significant predictor in CD patients. Comparing the cognitive distortion level, there were no significant differences between UC and CD patients although there was an increasing tendency according to the severity of depression or anxiety.

Conclusion If patients are accompanied by high levels of depression or anxiety and their associated risk factors including TNF- $\alpha$ agent or steroid use, it is recommended that not only symptoms are treated but also cognitive approach and evaluation be performed.

Psychiatry Investig 2020;17(11):1126-1136

Key Words Depression, Anxiety, Cognitive distortion, Inflammatory bowel disease.

\section{INTRODUCTION}

Inflammatory bowel disease (IBD), of which ulcerative colitis (UC) and Crohn's disease (CD) are two subset disorders, is an idiopathic disease with chronic or relapsing inflammation of the gastrointestinal tract. ${ }^{1,2}$ While the pathogenesis of IBD is unclear, it is currently understood that the complex interaction between genetic, environmental, and immunological factors contributes to the disease course and progression. ${ }^{3,4}$ In Korea, the incidence of UC and CD increased from 0.22 to

Received: August 5, 2020 Revised: October 8, 2020

Accepted: October 13, 2020

$\triangle$ Correspondence: Won Sub Kang, MD, PhD

Department of Psychiatry, Kyung Hee University College of Medicine, 23 Kyungheedae-ro Dongdaemun-gu, Seoul 02447, Republic of Korea

Tel: +82-2-958-8551, Fax: +82-2-957-1997, E-mail: menuhinwskang@khu.ac.kr

$\square$ Correspondence: Chang Kyun Lee, MD, PhD

Center for Crohn's and Colitis, Department of Gastroenterology, Kyung Hee University College of Medicine, 23 Kyungheedae-ro Dongdaemun-gu, Seoul 02447, Republic of Korea

Tel: +82-2-958-8258, Fax: +82-2-968-1848, E-mail: gidrlee@gmail.com

(c) This is an Open Access article distributed under the terms of the Creative Commons Attribution Non-Commercial License (https://creativecommons.org/licenses/bync/4.0) which permits unrestricted non-commercial use, distribution, and reproduction in any medium, provided the original work is properly cited.
3.62 and near 0 to 1.68 per 100,000, respectively, from 1986 to 2005. ${ }^{5}$

Patients with IBD have physical symptoms, such as diarrhea, rectal bleeding, and abdominal pain, and often develop various complications, including intestinal stricture, perforation, fistula, and abscess. Additionally, the disease's incurability and unpredictable clinical course have a negative impact on patients' quality of life and increase their psychological burden..$^{6-8}$ Previous studies have reported that a significant proportion of patients with IBD have high rates of psychiatric comorbidity, especially depression and anxiety. ${ }^{9,10}$ An inadequate treatment may lead to a vicious cycle of poor treatment compliance, hormonal changes, frequent relapse, and deterioration of disease. ${ }^{11-13}$ Therefore, it is important to discover depression and anxiety in patients with IBD and provide them with appropriate psychiatric treatment.

Various factors associated with depression or anxiety in patients with IBD have been suggested in previous studies, but few are consistently reported. Previously mentioned risk factors for depression in patients with UC are disease activity, hospitalization, sex, other concomitant diseases, and surgi- 
cal history. Risk factors for depression in patients with CD include disease activity, socioeconomic status, immunosuppressive drug use, surgical history, and age. In addition, the risk factors for anxiety are the time of diagnosis for UC and abdominal pain and socioeconomic status for CD. ${ }^{13-16}$ However, it was difficult to find a significant factor that consistently affects psychiatric symptoms in various studies. In addition, when comparing depression and anxiety levels in patients with UC and $\mathrm{CD}$, some studies reported that there were no significant differences, while some reported higher levels of psychiatric symptoms in patients with CD. ${ }^{17-19}$

Due to the chronic nature of IBD, which is difficult to treat and frequently recurs, the comorbidity of depression and anxiety also tends to become chronic during the long-term disease course. ${ }^{20}$ People who have chronic depression and anxiety often have cognitive distortions that lead to negative and pessimistic thoughts about their environment and themselves. ${ }^{21,22}$ It has been reported that not only the clinical symptoms of IBD itself but also the problems in life arising from the disease have a great influence on the course of treatment and compliance, but the rate of receiving treatment is low. ${ }^{23}$

Therefore, the objective of this study was to identify and compare the depression and anxiety levels of patients with UC and CD in Korea using well-established psychometric instruments. The factors affecting depression and anxiety of each disease were also analyzed. Furthermore, the cognitive distortion level during the long-term course of IBD and its correlation with depression and anxiety were examined.

\section{METHODS}

\section{Study patients}

This study was conducted at Kyung Hee University Hospital, Seoul, Republic of Korea, and included patients with a confirmed diagnosis of UC or CD who were evaluated and treated in the Department of Gastroenterology from March 2018 to June 2018. Diagnoses of UC and CD were made based on the established clinical, endoscopic, radiological, and histopathological criteria. ${ }^{24}$ All patients were asked to complete questionnaires proven reliable and valid in obtaining the relevant information required in this study. The exclusion criteria were refusal to participate in the study, inability to fully comprehend or complete the questionnaires, and history of psychiatry clinic visit. Written informed consent was obtained from all patients. The study protocol was approved by the Institutional Review Board of Kyung Hee University Hospital (KHUH 2018-01-083).

\section{Demographic and clinical presentation}

Patient demographic and clinical data were collected from electronic medical records and administered questionnaires. Sociodemographic variables, such as age, sex, educational level, employment status, income level, marital status, family history of IBD, body mass index (BMI), and smoking or alcohol use were recorded. The collected clinical data included disease type (UC vs. CD), disease duration after diagnosis, number of IBD-related hospitalizations and surgeries, medical treatment [5-aminosalicylic acid (5-ASA), immunosuppressant, corticosteroid, anti-tumor necrosis factor-alpha (anti-TNF- $\alpha$ ), and others], history of treatment discontinuation, and presence of comorbidities. Disease activity was assessed using the partial Mayo Clinic score ${ }^{25}$ for UC and Harvey Bradshaw in$\mathrm{dex}^{26}$ for CD.

\section{Psychometric tools}

\section{Patient Health Questionnaire-9 (PHQ-9)}

The PHQ-9 is a well-validated depression screening tool, which is a self-reporting questionnaire consisting of nine items that are used to assess the depression level over the past 2 weeks. Each item is scored on a 4-point Likert scale (0-3), so the total score can range between 0 and 27 . Scores of $0-4,5-$ 9, 10-14, 15-19, and 20-27 indicate minimal, mild, moderate, moderately severe, and severe depression, respectively. According to earlier studies, an individual with PHQ-9 score $\geq 10$ is interpreted as having major depression with a sensitivity of approximately $90 \%$ and specificity of $77-88 \% .^{27-30}$

\section{Hospital and Anxiety Depression Scale (HADS)}

The HADS, originally devised by Zigmond and Snaith in 1983 , is a self-reporting questionnaire to measure the levels of anxiety (A) and depression (D). ${ }^{31}$ Each scale comprises seven items, and each item on the questionnaire is scored on a 4 -point Likert scale ( $0-3)$. Thus, one can score between 0 and 21 for either anxiety or depression. A higher score depicts a greater level of anxiety and depression. Cutoff scores are available where scores $<8$ are considered non-cases, $8-10$ as mild, 11-14 as moderate, and 15-21 as severe cases of psychological morbidity. ${ }^{32}$ A score $\geq 11$ indicates clinically significant depression. ${ }^{31,33}$ Since the HADS focuses on non-physical symptoms, it is useful in assessing anxiety and depression in patients with significant physical or chronic illness.

\section{Anxious Thoughts and Tendencies (AT\&T) Scale}

The AT\&T scale, originally developed by Ganellen et al. ${ }^{34}$ and later revised by Uhlenhuth et al., ${ }^{35}$ is an instrument designed to identify anxiety-prone cognitive style. Such cognitive style is marked by cognitive distortions, including catastrophizing, intrusive negative thoughts, and selective abstraction focusing on negative aspects of a situation. It contains 15 items 
on a 4-point Likert scale (0-3), with a higher score representing a greater predisposition to anxiety in general. According to the study by Uhlenhuth et al., ${ }^{35}$ AT\&T scores observed in individuals with all anxiety disorders were higher than those in individuals in the reference group, with the highest scores observed in individuals who have panic disorder with agoraphobia. The second highest scores were noted in those with generalized social phobia, while the lowest scores were observed in individuals with specific social phobias.

\section{Statistical analysis}

In the comparative analysis of patients with UC and CD, categorical variables were analyzed using chi-square test or Fisher's exact test, while continuous variables were analyzed using Wilcoxon rank sum test. In the subgroups (UC and CD), we analyzed the variables that were correlated with different levels of depression and anxiety defined by PHQ-9, HADS-D, and HADS-A.

PHQ-9 scores were subcategorized into $0-4,5-9$, and $\geq 10$, and HADS-A and D scores were subcategorized into $0-7,8^{-}$ 10 , and $\geq 11$. In the comparison of the three ordinal groups, categorical variables were analyzed using chi-square test (or Fisher's exact test), and continuous variables were analyzed using the Jonckheere-Terpstra test. Furthermore, after screen- ing variables with $\mathrm{p}$-value $<0.1$ through simple multinomial logistic regression, multiple multinomial logistic regression was performed with selected variables. In addition, multiple generalized linear model (GLM) was established to examine the association between AT\&T and depression or anxiety scales (PHQ-9, HADS-D, and HADS-A).

The $\mathrm{p}$-value of all analyses was based on the significance level of 0.05 , and statistical analyses were performed using the SAS 9.4 program (SAS Institute Inc., Cary, NC, USA).

\section{RESULTS}

\section{Demographic and clinical characteristics}

Of the 369 patients with IBD enrolled in the study, 187 had UC (50.7\%), while 182 had CD (49.3\%). Table 1 demonstrates baseline sociodemographic characteristics of the study population. The mean age of patients with CD was lower than that of patients with UC $(33.83 \pm 11.37$ vs. $45.46 \pm 14.09$ years, $\mathrm{p}<0.001)$. In both UC and CD groups, there were more men than women $(60.96 \%$ in UC, $75.82 \%$ in CD). There was a larger number of patients with $\mathrm{CD}$ with education level of university graduation or higher compared to that of patients with UC $(62.09 \%$ vs. $52.94 \%, \mathrm{p}<0.001)$. When the patients' marital statuses were collected, there were more patients with UC

Table 1. Demographic characteristics of the study population

\begin{tabular}{|c|c|c|c|}
\hline Variable & $\mathrm{UC}(\mathrm{N}=187)$ & $\mathrm{CD}(\mathrm{N}=182)$ & $\mathrm{p}$-value \\
\hline Age (year) & $45.46 \pm 14.09$ & $33.83 \pm 11.37$ & $<0.001^{*}$ \\
\hline Sex & & & $0.002 *$ \\
\hline Male & $114(60.96)$ & $138(75.82)$ & \\
\hline Female & $73(39.04)$ & $44(24.18)$ & \\
\hline $\mathrm{BMI}\left(\mathrm{kg} / \mathrm{m}^{2}\right)$ & $23.04 \pm 2.87$ & $22.28 \pm 3.63$ & $0.003^{*}$ \\
\hline Alcohol use & $82(43.85)$ & $89(48.90)$ & 0.331 \\
\hline \multicolumn{4}{|l|}{ Smoking } \\
\hline Current smoker & $19(10.16)$ & $30(16.48)$ & 0.074 \\
\hline \multicolumn{4}{|l|}{ Education level } \\
\hline University graduation or high & $99(52.94)$ & $113(62.09)$ & $<0.001^{*}$ \\
\hline Marital status & & & $<0.001^{*}$ \\
\hline Married & $116(62.03)$ & $76(41.76)$ & \\
\hline Never married & $59(31.55)$ & $102(56.04)$ & \\
\hline Divorced/separated/widowed & $12(6.42)$ & $4(2.2)$ & \\
\hline Employment status, working & $141(75.40)$ & $149(81.87)$ & 0.155 \\
\hline Income & & & 0.057 \\
\hline Low & $49(26.35)$ & $66(36.67)$ & \\
\hline Moderate & $71(38.17)$ & $67(37.22)$ & \\
\hline High & $66(35.48)$ & $47(26.11)$ & \\
\hline Family history of IBD & $17(9.09)$ & $12(6.59)$ & 0.373 \\
\hline
\end{tabular}

Data are presented as mean \pm SD or number $(\%) .{ }^{*} \mathrm{p}<0.05$. UC: ulcerative colitis, CD: Crohn's disease, BMI: body mass index, IBD: inflammatory bowel disease 
who were married or separated than were patients with CD. In patients with UC, the number of never married individuals was higher than that in patients with $\mathrm{CD}$. There were no significant differences in alcohol or tobacco use, family history of IBD, employment status, and income between patients with UC and CD.

The clinical characteristics of the study population are shown in Table 2. Patients with UC had a higher rate of disease remission, while there was a larger number of patients with $\mathrm{CD}$ with mild or moderate to severe disease activity. Patients with UC more frequently used 5-ASA, whereas patients with CD more frequently used immunosuppressant and anti-TNF- $\alpha$. IBD-related hospitalizations or surgeries and history of steroid or biologics use were all significantly more common in patients with CD compared to those in patients with UC. Moreover, there was a higher rate of treatment discontinuation in patients with CD than in patients with UC. No significant differences in disease duration and presence of comorbidity existed between the two groups.

\section{Psychosocial comorbidities}

Table 3 shows the average scores of psychometric scales used in the study population. The average scores of PHQ-9 and HADS in both patients with UC and CD were below the cutoff scores for mild depression or anxiety although the

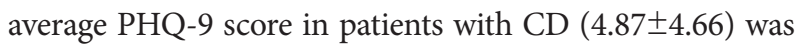
extremely close to the cutoff score of 5 . There were no significant differences in the average scores between the UC and

Table 3. Average scores of depression and anxiety in patients with UC/CD

\begin{tabular}{lrrc}
\hline \multicolumn{1}{c}{ Scale } & $\mathrm{UC}(\mathrm{N}=187)$ & $\mathrm{CD}(\mathrm{N}=182)$ & $\mathrm{p}$-value \\
\hline PHQ-9 & $4.06 \pm 3.99$ & $4.87 \pm 4.66$ & 0.128 \\
HADS-D & $5.15 \pm 3.48$ & $5.42 \pm 3.78$ & 0.740 \\
HADS-A & $4.32 \pm 3.68$ & $4.40 \pm 3.33$ & 0.492 \\
AT\&T & $22.65 \pm 7.78$ & $22.19 \pm 6.72$ & 0.795 \\
\hline
\end{tabular}

Data are presented as mean \pm SD. UC: ulcerative colitis, CD: Crohn's disease, PHQ-9: Patient Health Questionnaire-9, HADS-D: Hospital and Anxiety Depression Scale-Depression, HADS-A: Hospital and Anxiety Depression Scale-Anxiety, AT\&T: Anxious Thoughts and Tendencies Scale

Table 2. Clinical and therapeutic characteristics of the study population

\begin{tabular}{|c|c|c|c|}
\hline & $\mathrm{UC}(\mathrm{N}=187)$ & $\mathrm{CD}(\mathrm{N}=182)$ & $\mathrm{p}$-value \\
\hline Disease duration (year) & $8.98 \pm 7.70$ & $9.28 \pm 5.39$ & 0.138 \\
\hline Disease activity & & & $<0.001^{*}$ \\
\hline Remission & $104(55.61)$ & $43(23.63)$ & \\
\hline Mild & $54(28.88)$ & $82(45.05)$ & \\
\hline Moderate to severe & $29(15.51)$ & $57(31.32)$ & \\
\hline Presence of comorbidity & $7(3.72)$ & $9(4.92)$ & 0.571 \\
\hline $\mathrm{DM}$ & $2(1.07)$ & $3(1.65)$ & 0.682 \\
\hline Malignancy & $3(1.60)$ & $3(1.65)$ & 1.000 \\
\hline Liver disease & $2(1.07)$ & $1(0.55)$ & 1.000 \\
\hline Cerebrovascular accident & 0 & $1(0.55)$ & 0.493 \\
\hline Myocardial infarction & 0 & $2(1.10)$ & 0.243 \\
\hline Others (CHF, COPD, AIDS, dementia, peripheral vascular disease) & 0 & 0 & \\
\hline \multicolumn{4}{|l|}{ Current treatment } \\
\hline 5-aminosalicylic acid & $174(93.05)$ & $144(79.12)$ & $<0.001^{*}$ \\
\hline Immunosuppressant (azathiopurine, 6-MP, MTX) & $84(44.92)$ & $113(62.09)$ & $<0.001^{*}$ \\
\hline Steroid & $9(4.81)$ & $6(3.30)$ & 0.461 \\
\hline Anti-TNF alpha (infliximab, adlimumab, golimumab) & $35(18.72)$ & $124(68.13)$ & $<0.001^{*}$ \\
\hline Others (filgotinib, tofacitinib, ustekinumab, vedolizumab) & $30(16.04)$ & $11(6.04)$ & $0.002^{*}$ \\
\hline Number of IBD-related hospitalizations & $0.78 \pm 1.34$ & $1.51 \pm 1.83$ & $<0.001^{*}$ \\
\hline Number of IBD-related surgeries & $0.06 \pm 0.42$ & $0.60 \pm 0.89$ & $<0.001^{*}$ \\
\hline History of steroid use & $114(60.96)$ & $129(70.88)$ & $0.037^{*}$ \\
\hline History of biologics use & $63(33.69)$ & $115(63.19)$ & $<0.001^{*}$ \\
\hline History of treatment discontinuation & $2(1.07)$ & $11(6.04)$ & $0.010^{*}$ \\
\hline
\end{tabular}

Data are presented as mean \pm SD or number $(\%) .{ }^{*} \mathrm{p}<0.05$. UC: ulcerative colitis, CD: Crohn's disease, IBD: inflammatory bowel disease 
CD groups. The depression and anxiety levels in patients with IBD assessed using the PHQ-9 and HADS are presented in Table 4. More patients with CD had mild or moderate to severe depression than did patients with UC based on the PHQ9 scores, but the difference was not statistically significant. In addition, the level of depression measured using the HADS$\mathrm{D}$ was not significantly different in the two groups. The number of patients with mild or moderate to severe levels of anxiety measured using the HADS-A was slightly larger in the UC group than in the CD group, yet the difference was not statistically significant.

\section{Multivariable analysis of factors associated with depression in patients with IBD}

Using the established cutoff scores of 5 and 10 for PHQ-9 and 8 and 11 for HADS-D, the study patients were categorized into subgroups of mild depression and suspected clinically significant depression based on each scale. The subgroup with mild depression included patients with PHQ-9 scores of 5-9 and HADS-D scores of 8-10. The other subgroups with suspicious clinically significant depression were comprised of patients with PHQ-9 score $\geq 10$ and HADS-D score $\geq 11$.

In patients with UC, divorced, separated, or widowed status and treatment with anti-TNF- $\alpha$ were significantly associated with mild depression based on the PHQ-9 scale. Age was also associated with this subgroup with an odds ratio of 0.93 , suggesting that younger age was associated with mild depression. In the suspicious clinically significant depression

Table 4. Depression and anxiety levels in patients with UC/CD

\begin{tabular}{lccc}
\hline \multicolumn{1}{c}{ Scale } & UC & $\mathrm{CD}$ & p-value \\
& $(\mathrm{N}=187)$ & $(\mathrm{N}=182)$ & \\
\hline PHQ-9 & & \multicolumn{3}{c}{0.101} \\
None $(<5)$ & $121(64.71)$ & $101(55.50)$ & \\
Mild (5-9) & $49(26.20)$ & $53(29.12)$ & \\
Moderate to severe (10-27) & $17(9.09)$ & $28(15.38)$ & \\
HADS-D & & & 0.957 \\
None (<8) & $142(75.94)$ & $136(74.72)$ & \\
Mild (8-10) & $26(13.90)$ & $26(14.29)$ & \\
Moderate to severe (11-21) & $19(10.16)$ & $20(10.99)$ & \\
HADS-A & & & 0.269 \\
None $(<8)$ & $150(80.21)$ & $157(86.26)$ & \\
Mild $(8-10)$ & $23(12.30)$ & $17(9.34)$ & \\
Moderate to severe (11-21) & $14(7.49)$ & $8(4.40)$ & \\
\hline
\end{tabular}

Data are presented as number (\%). UC: ulcerative colitis, CD: Crohn's disease, IBD: inflammatory bowel disease, PHQ-9: Patient Health Questionnaire-9, HADS-D: Hospital and Anxiety Depression Scale-Depression, HADS-A: Hospital and Anxiety Depression Scale-Anxiety group with PHQ-9 score $\geq 10$, BMI was a significant predictor of depression with an odds ratio of 0.81 . When categorized by HADS-D, never married status in patients with UC was significantly associated with suspicious clinically significant depression (Table 5).

In patients with $\mathrm{CD}$, alcohol use and never married status had significant association with mild depression assessed using the PHQ-9 scale. Employment at the time of survey had an odds ratio of 0.15 in the group with suspicious clinically significant depression assessed using the PHQ-9 scale, indicating that having a job had protective effect against depression. Moderate to severe disease activity had strong association with both mild and suspicious clinically significant depression assessed using the PHQ-9 scale. We found no significant predictor of depression in patients with $\mathrm{CD}$ when the HADS-D was used (Table 6).

\section{Multivariable analysis of factors associated with anxiety in patients with IBD}

The same cutoff scores of 8 and 11 were used in the HADSA to categorize patients into subgroups with mild anxiety and suspicious clinically significant anxiety. In patients with UC, female sex had a significant association with mild anxiety, while never married status was associated with suspicious clinically significant anxiety (Table 7). In patients with CD, steroid use had a strong association with mild depression with an odds ratio of 17.03 (Table 8). However, this result may be of limited value since there were only six patients with CD who used steroid.

\section{Association between anxiety-prone cognitive style and depression or anxiety level}

The average AT\&T scale scores were not significantly different between patients with UC and CD. When the patients were categorized according to the depression or anxiety levels based on the PHQ-9 and HADS, there was no significant difference in the average AT\&T scores between patients with UC and CD. However, as the depression or anxiety level increased, the average AT\&T scores also significantly increased in both patients with UC and CD $(\mathrm{p}<0.001)$ (Table 9). We obtained the same results after adjusting for other significant variables (UC, disease activity; $\mathrm{CD}$, alcohol use, marital status, employment status, income) in the GLM ( $\mathrm{p}<0.001)$.

\section{DISCUSSION}

This study aimed to investigate the depression and anxiety levels, risk factors, and accompanying cognitive distortion in patients with IBD. The average depression and anxiety levels in patients with IBD were not clinically significant. How- 
ever, $35 \%$ of patients with UC and $45 \%$ of patients with CD complained of feeling depressive based on the PHQ-9 scale, whereas $25 \%$ of patients with UC and those with CD had depressive mood based on the HADS-D. In addition, $20 \%$ of patients with UC and $14 \%$ of patients with CD complained of anxiety. The risk factors for depression were marital status, use of anti-TNF- $\alpha$, age, and BMI in patients with UC, and alcohol use, marital status, employment status, and disease activity in patients with $\mathrm{CD}$. The risk factors related to anxiety were sex and marital status in patients with UC, and steroid use in patients with $\mathrm{CD}$. As the depression and anxiety levels increased in patients with UC and $\mathrm{CD}$, the cognitive distortion level also significantly increased.

In this study, the level of depression was measured using two different psychometric tools; PHQ-9 and HADS-D. The PHQ-9 is based on the Diagnostic and Statistical Manual of Mental Disorders (DSM-IV) and assesses depressive symptom criteria whereas HADS-D focuses more on non-physi- cal symptoms by emphasizing emotional aspect of depression. ${ }^{36}$ The number of mildly depressive patients were higher based on PHQ-9 compared with HADS-D, which may be due to physical symptoms caused by IBD. Based on both depression scales used in this study, never married or separated status was a significant risk factor of depression in patients with UC and CD. In addition, never married status was a significant risk factor of anxiety in patients with UC. In patients with $\mathrm{CD}$, the anxiety level was higher in patients who were never married compared to married patients, although the difference was not statistically significant. A weak support system is a known risk factor for depression or anxiety, ${ }^{37}$ and it is believed that marriage is an important factor constituting the support system of patients. Particularly, the support system becomes more important when considering characteristics of diseases that need to be treated and managed on a longterm basis. Moreover, current employment status is one of the important indicators reflecting the patient's daily life mainte-

Table 5. Multivariable analysis of factors associated with depression in patients with UC

\begin{tabular}{|c|c|c|c|c|c|c|}
\hline & \multicolumn{3}{|c|}{ PHQ-9: 5-9 } & \multicolumn{3}{|c|}{ PHQ-9 $\geq 10$} \\
\hline & OR & $95 \% \mathrm{CI}$ & p-value & OR & $95 \% \mathrm{CI}$ & p-value \\
\hline \multicolumn{7}{|l|}{ Education level } \\
\hline University graduation or high & 0.48 & $0.19-1.22$ & 0.123 & 3.40 & $0.67-17.33$ & 0.142 \\
\hline Married & 1.00 & & & 1.00 & & \\
\hline Never married & 1.26 & $0.47-3.41$ & 0.647 & 2.62 & $0.73-9.46$ & 0.142 \\
\hline Divorced/separated/widowed & 7.72 & $1.90-31.41$ & $0.004^{*}$ & $\inf$ & $\inf$ & 0.979 \\
\hline Anti-TNF- $\alpha$ & 4.34 & $1.64-11.49$ & $0.003^{*}$ & 0.88 & $0.16-4.81$ & 0.884 \\
\hline History of steroid use & 2.32 & $0.97-5.55$ & 0.060 & 0.85 & $0.26-2.76$ & 0.791 \\
\hline Age & 0.93 & $0.89-0.97$ & $0.002^{*}$ & 0.98 & $0.94-1.04$ & 0.545 \\
\hline \multirow[t]{3}{*}{ BMI } & 1.02 & $0.89-1.17$ & 0.796 & 0.81 & $0.66-1.00$ & $0.047^{*}$ \\
\hline & \multicolumn{3}{|c|}{ HADS-D: $8-10$} & \multicolumn{3}{|c|}{ HADS-D $\geq 11$} \\
\hline & OR & $95 \% \mathrm{CI}$ & p-value & OR & $95 \% \mathrm{CI}$ & $\mathrm{p}$-value \\
\hline Alcohol use & 0.81 & $0.31-2.16$ & 0.675 & 0.35 & $0.08-1.45$ & 0.148 \\
\hline Married & 1.00 & & & 1.00 & & \\
\hline Never married & 0.60 & $0.22-1.65$ & 0.321 & 3.83 & $1.18-12.42$ & $0.026^{*}$ \\
\hline Divorced/separated/widowed & $\inf$ & inf & 0.970 & 1.73 & $0.24-12.61$ & 0.588 \\
\hline Employment status, working & 0.84 & $0.30-2.38$ & 0.740 & 0.45 & $0.14-1.43$ & 0.175 \\
\hline \multicolumn{7}{|l|}{ Disease activity } \\
\hline Remission & 1.00 & & & 1.00 & & \\
\hline Mild & 0.56 & $0.20-1.59$ & 0.276 & 0.22 & $0.05-1.10$ & 0.065 \\
\hline Moderate to severe & 0.91 & $0.27-3.09$ & 0.883 & 0.67 & $0.15-2.95$ & 0.600 \\
\hline $\begin{array}{l}\text { Other (filgotinib, tofacitinib, ustekinumab, } \\
\text { vedolizumab) }\end{array}$ & 1.97 & $0.60-6.44$ & 0.263 & 2.56 & $0.68-9.64$ & 0.164 \\
\hline BMI & 0.92 & $0.78-1.08$ & 0.282 & 0.91 & $0.73-1.13$ & 0.378 \\
\hline
\end{tabular}

Multivariable analysis was performed after selecting variables with $\mathrm{p}<0.1$ from univariate logistic regression analysis. ${ }^{*} \mathrm{p}<0.05$, the references for comparative analysis were 0-4 for PHQ-9 and 0-7 for HADS-D. UC: ulcerative colitis, PHQ-9: Patient Health Questionnaire-9, HADS: Hospital and Anxiety Depression Scale, anti-TNF- $\alpha$ : anti-tumor necrosis factor-alpha, BMI: body mass index, OR: odds ratio, CI: confidence interval, inf: infinite 
nance, and it is consistent with the results of previous studies, which revealed that socioeconomic deprivation was an important factor in depression. ${ }^{15,38,39}$ In this study, employed patients with CD had lower risk of developing depression compared to unemployed patients. Although not statistically significant, a similar trend was observed in patients with UC.

In the case of the therapeutic agent, the use of anti-TNF- $\alpha$ agent increased the risk of having depressive mood in pa- tients with UC based on the PHQ-9 scale. Anti-TNF- $\alpha$ agents include infliximab, adalimumab, and golimumab, of which infliximab is the most commonly used. Generally, topical or oral 5-ASA or oral steroid is initially administered in the treatment sequence; then, immunosuppressants and biologics, such as anti-TNF- $\alpha$ agents, are administered if symptoms persist. ${ }^{40}$ It can be assumed that the frustration experienced by the patient during this process may be the cause of depression.

Table 6. Multivariable analysis of factors associated with depression in patients with CD

\begin{tabular}{|c|c|c|c|c|c|c|}
\hline & \multicolumn{3}{|c|}{ PHQ-9: 5-9 } & \multicolumn{3}{|c|}{ PHQ-9 $\geq 10$} \\
\hline & OR & $95 \% \mathrm{CI}$ & p-value & OR & $95 \% \mathrm{CI}$ & p-value \\
\hline Alcohol use & 2.16 & $1.02-4.58$ & $0.045^{*}$ & 1.71 & $0.63-4.65$ & 0.296 \\
\hline Married & 1.00 & & & & & \\
\hline Never married & 2.86 & $1.04-7.84$ & $0.041^{*}$ & 1.80 & $0.47-6.88$ & 0.391 \\
\hline Divorced/separated/widowed & $\inf$ & $\inf$ & 0.979 & $\inf$ & $\inf$ & 0.987 \\
\hline Employment status, working & 0.63 & $0.18-2.22$ & 0.468 & 0.15 & $0.04-0.67$ & $0.012^{*}$ \\
\hline \multicolumn{7}{|l|}{ Income } \\
\hline Low & 1.00 & & & 1.00 & & \\
\hline Moderate & 0.76 & $0.27-2.11$ & 0.596 & 1.01 & $0.25-4.10$ & 0.992 \\
\hline High & 0.64 & $0.20-2.12$ & 0.466 & 0.97 & $0.16-5.87$ & 0.972 \\
\hline \multicolumn{7}{|l|}{ Disease activity } \\
\hline Remission & 1.00 & & & & & \\
\hline Mild & 1.65 & $0.64-4.24$ & 0.300 & 3.82 & $0.86-16.95$ & 0.078 \\
\hline Moderate to severe & 3.28 & $1.16-9.23$ & $0.025^{*}$ & 10.82 & $2.30-51.01$ & $0.003^{*}$ \\
\hline Steroid & 4.78 & $0.38-60.19$ & 0.226 & 3.11 & $0.17-58.59$ & 0.448 \\
\hline \multirow[t]{3}{*}{ Age } & 1.04 & $0.99-1.09$ & 0.098 & 0.95 & $0.88-1.02$ & 0.169 \\
\hline & \multicolumn{3}{|c|}{ HADS-D: $8-10$} & \multicolumn{3}{|c|}{ HADS-D $\geq 11$} \\
\hline & OR & $95 \% \mathrm{CI}$ & $\mathrm{p}$-value & OR & $95 \% \mathrm{CI}$ & p-value \\
\hline Female & 0.39 & $0.10-1.54$ & 0.180 & 0.70 & $0.16-3.02$ & 0.631 \\
\hline Married & 1.00 & & & 1.00 & & \\
\hline Never married & 1.40 & $0.36-5.36$ & 0.627 & 1.32 & $0.31-5.71$ & 0.711 \\
\hline Divorced/separated/widowed & $\inf$ & $\inf$ & 0.985 & $\inf$ & $\inf$ & 0.987 \\
\hline Employment status, working & 0.72 & $0.15-3.48$ & 0.681 & 0.22 & $0.04-1.13$ & 0.070 \\
\hline \multicolumn{7}{|l|}{ Income } \\
\hline Low & 1.00 & & & 1.00 & & \\
\hline Moderate & 0.93 & $0.24-3.63$ & 0.913 & 0.49 & $0.07-3.66$ & 0.488 \\
\hline High & 1.05 & $0.22-4.94$ & 0.951 & 3.69 & $0.61-22.29$ & 0.155 \\
\hline \multicolumn{7}{|l|}{ Disease activity } \\
\hline Remission & 1.00 & & & 1.00 & & \\
\hline Mild & 1.43 & $0.39-5.22$ & 0.586 & 2.01 & $0.45-8.93$ & 0.358 \\
\hline Moderate to severe & 3.29 & $0.90-12.01$ & 0.071 & 2.50 & $0.54-11.65$ & 0.244 \\
\hline Steroid & 5.99 & $0.41-87.05$ & 0.190 & 12.42 & $0.93-165.31$ & 0.056 \\
\hline Anti-TNF- $\alpha$ & 0.42 & $0.17-1.08$ & 0.071 & 0.55 & $0.18-1.69$ & 0.298 \\
\hline Age & 1.01 & $0.96-1.07$ & 0.686 & 0.98 & $0.92-1.05$ & 0.623 \\
\hline
\end{tabular}

Multivariable analysis was performed after selecting variables with $\mathrm{p}<0.1$ from univariate logistic regression analysis. ${ }^{*} \mathrm{p}<0.05$, the references for comparative analysis were 0-4 for PHQ-9 and 0-7 for HADS-D. CD: Crohn's disease, PHQ-9: Patient Health Questionnaire-9, HADS: Hospital and Anxiety Depression Scale, anti-TNF- $\alpha$ : anti-tumor necrosis factor-alpha, OR: odds ratio, CI: confidence interval, inf: infinite 
Table 7. Multivariable analysis of factors associated with anxiety in patients with UC

\begin{tabular}{|c|c|c|c|c|c|c|}
\hline & \multicolumn{3}{|c|}{ HADS-A: 8-10 } & \multicolumn{3}{|c|}{ HADS-A $\geq 11$} \\
\hline & OR & $95 \% \mathrm{CI}$ & $\mathrm{p}$-value & OR & $95 \% \mathrm{CI}$ & $\mathrm{p}$-value \\
\hline Female & 4.15 & $1.32-13.04$ & $0.015^{*}$ & 1.10 & $0.30-4.02$ & 0.882 \\
\hline Alcohol use & 0.79 & $0.26-2.36$ & 0.666 & 0.43 & $0.10-1.86$ & 0.256 \\
\hline Married & 1.00 & & & 1.00 & & \\
\hline Never married & 2.12 & $0.74-6.10$ & 0.162 & 5.03 & $1.16-21.76$ & $0.031^{*}$ \\
\hline Divorced/separated/widowed & inf & inf & 0.968 & 4.19 & $0.57-30.79$ & 0.160 \\
\hline Employment status, working & 1.59 & $0.42-6.01$ & 0.497 & 0.21 & $0.04-1.03$ & 0.054 \\
\hline \multicolumn{7}{|l|}{ Income } \\
\hline Low & 1.00 & & & 1.00 & & \\
\hline Moderate & 0.56 & $0.16-1.97$ & 0.364 & 1.44 & $0.25-8.23$ & 0.680 \\
\hline High & 0.78 & $0.18-3.43$ & 0.742 & 3.91 & $0.64-23.80$ & 0.139 \\
\hline History of biologics use & 0.51 & $0.14-1.78$ & 0.289 & 1.06 & $0.30-3.76$ & 0.931 \\
\hline History of steroid use & 0.52 & $0.19-1.45$ & 0.210 & 1.67 & $0.40-7.06$ & 0.486 \\
\hline BMI & 0.87 & $0.71-1.06$ & 0.175 & 0.94 & $0.72-1.22$ & 0.623 \\
\hline
\end{tabular}

Multivariable analysis was performed after selecting variables with $\mathrm{p}<0.1$ from univariate logistic regression analysis. ${ }^{*} \mathrm{p}<0.05$, the references for comparative analysis were 0-7 for HADS-A. UC: ulcerative colitis, HADS: Hospital and Anxiety Depression Scale, BMI: body mass index, OR: odds ratio, $\mathrm{CI}$ : confidence interval, inf: infinite

Table 8. Multivariable analysis of factors associated with anxiety in patients with $C D$

\begin{tabular}{|c|c|c|c|c|c|c|}
\hline & \multicolumn{3}{|c|}{ HADS-A: 8-10 } & \multicolumn{3}{|c|}{ HADS-A $\geq 11$} \\
\hline & OR & $95 \% \mathrm{CI}$ & $\mathrm{p}$-value & OR & $95 \% \mathrm{CI}$ & p-value \\
\hline History of treatment discontinuation & inf & inf & 0.971 & 1.03 & $0.06-17.30$ & 0.981 \\
\hline 5-aminosalicylic acid & 1.22 & $0.25-5.84$ & 0.807 & 0.35 & $0.06-1.91$ & 0.224 \\
\hline Steroid & 17.03 & $2.24-129.20$ & $0.006^{*}$ & 9.82 & $0.55-174.14$ & 0.119 \\
\hline Anti-TNF- $\alpha$ & 0.42 & $0.15-1.23$ & 0.113 & 0.61 & $0.12-3.15$ & 0.559 \\
\hline
\end{tabular}

Multivariable analysis was performed after selecting variables with $\mathrm{p}<0.1$ from univariate logistic regression analysis. ${ }^{*} \mathrm{p}<0.05$, the references for comparative analysis were 0-7 for HADS-A. CD: Crohn's disease, HADS: Hospital and Anxiety Depression Scale, anti-TNF- $\alpha$ : anti-tumor necrosis factor-alpha, OR: odds ratio, CI: confidence interval, inf: infinite

Table 9. Average scores of AT\&T scale according to the level of depression and anxiety in patients with IBD

\begin{tabular}{ccccc}
\hline & PHQ-9: 0-4 & PHQ-9: 5-9 & PHQ-9: 10-21 & p-value \\
\hline UC & $19.87 \pm 5.47$ & $25.41 \pm 7.64$ & $34.53 \pm 8.50$ & $<0.001^{*}$ \\
CD & $19.01 \pm 4.57$ & $24.00 \pm 5.18$ & $30.21 \pm 7.92$ & $<0.001^{*}$ \\
\hline & HADS-D: 0-7 & HADS-D: 8-10 & HADS- D: 11-21 & p-value \\
\hline UC & $20.11 \pm 5.54$ & $28.50 \pm 7.87$ & $33.68 \pm 8.34$ & $<0.001^{*}$ \\
CD & $20.40 \pm 5.39$ & $26.38 \pm 6.80$ & $28.90 \pm 8.30$ & $<0.001^{*}$ \\
\hline & HADS-A: 0-7 & HADS-A: 8-10 & HADS-A: $11-21$ & p-value \\
\hline UC & $19.91 \pm 4.79$ & $31.48 \pm 6.83$ & $37.50 \pm 7.84$ & $<0.001^{*}$ \\
CD & $20.44 \pm 4.58$ & $30.12 \pm 6.03$ & $39.63 \pm 6.97$ & $<0.001^{*}$ \\
\hline
\end{tabular}

${ }^{*} \mathrm{p}<0.05$, ${ }^{\dagger}$ adjusting for other significant variables (UC: disease activity, CD: alcohol use, marital status, employment status, income) in generalized linear model. IBD: inflammatory bowel disease, UC: ulcerative colitis, CD: Crohn's disease, AT\&T scale: Anxious Thoughts and Tendencies scale, PHQ-9: Patient Health Questionnaire-9, HADS: Hospital and Anxiety Depression Scale
Moreover, patients are required to visit the clinic every week for both induction and maintenance of anti-TNF- $\alpha$ agent, which is administered intravenously. Again, this may cause daily and work life discomfort and disturbances and deteriorate the patient's quality of life.

Increased disease activity in patients with IBD is a known risk factor of psychological distress. According to Precelli et al., ${ }^{41}$ various intestinal and extra-intestinal symptoms related to moderate to severe disease activity in IBD may lead to discomfort and frustration, thereby increasing the risk of depression. Although it appears to be a risk factor for depression in UC as well, it was not statistically significant, and it can be expected that patients with $\mathrm{CD}$ have increased risk of depression because there have been reports that $\mathrm{CD}$ has a more chronic course compared to UC and can be accompanied by abdominal pain even in remission. ${ }^{42}$

In patients with UC, the risk of developing depression 
somewhat decreased as the age increased by 1 year. Young people are more socially active than middle-aged individuals and thus may be at a greater risk of depression resulting from decreased quality of life associated with IBD. ${ }^{43,44}$ In addition, the risk of depression somewhat decreased as BMI increased by 1 unit. Already, a positive correlation between obesity and depression has been demonstrated in many studies. ${ }^{45-47}$ However, the average BMI of patients with UC participating in this study was normal at 22.28, and malnutrition in patients with IBD is one of the targets of treatment. Considering that the disease causes abdominal pain or discomfort or that dietary control is sensitive due to the nature of the disease, proper oral intake may be linked to an effect of preventing depressive symptoms. ${ }^{48}$ Given this, increased BMI can be understood as a result that reflects the patient's proper dietary intake.

The risk factors of anxiety, other than previously mentioned marital status, include female sex and steroid use. Considering that the prevalence of anxiety disorders is higher in women than in men, ${ }^{49}$ it can be assumed that women with IBD are more susceptible to anxiety. In this study, female sex was a significant predictor of anxiety in patients with UC. Although not statistically significant, more female patients with $\mathrm{CD}$ had anxiety than male patients with $\mathrm{CD}$ did. Women with IBD may frequently develop anxiety in marriage, pregnancy, childbirth, lactation, and parenting due to the chronic course of illness and treatment. ${ }^{50}$ Steroid use was another predictor of anxiety in patients with $\mathrm{CD}$. This may be due to the side effects of steroids, such as weight gain, moon face, acne caused by hormonal changes, and osteoporosis. ${ }^{44,51,52}$ However, there were only nine patients with steroid treatment in the UC subgroup, so further research on a larger study population is needed.

Catastrophic thinking refers to distorting the irrational negative perception of the consequences of a particular event. In this process, the patient has emotional burden, adversely affecting the result of rational coping and treatment and compliance, which can be used to measure the tendency of anxiety vulnerable accidents through the AT\&T scale. In this study, the mean AT\&T scores significantly increased as the severity of depression and anxiety assessed using PHQ-9, HADS-D, and HADS-A increased. According to Khawaja and Dyer, ${ }^{53}$ the mean AT\&T scores were 26.01 in the control group and 39.15 in patients with anxiety disorder. In another study by Lee at al., ${ }^{54}$ the mean AT\&T scores were 23.47 in the control group and 29.83 in patients with panic disorder with or without agoraphobia. This result reflects changes in cognitive distortions, such as catastrophes, that occur when psychiatric symptoms, such as depression and anxiety, are present for a long time. In this study, a significant cognitive distortion level was observed when depression and anxiety levels were mod- erate or higher. In particular, when the anxiety level assessed using the HADS-A was moderate to severe, the AT\&T scores were 37.50 in patients with UC and 39.63 in patients with CD. Cognitive distortion also causes the tendency to recognize and judge situations as extreme or negative. Considering this, it is important to check the depression and anxiety level periodically in patients with IBD and consult the department of psychiatry, especially if it is prolonged. As mentioned earlier, it should be considered whether there is cognitive distortion and, if any, cognitive therapy is necessary. Given that cognitive distortion was a significant outcome variable in this study, further studies on the correlation between cognitive distortion and depression or anxiety may provide more advanced results. To date, few studies have yet examined the relationship between disease specific factors and cognitive style in IBD patients. Thus, further study on a wider spectrum of cognitive characteristics of IBD patients by using various tools, in addition to catastrophic thinking identified by AT\&T may be needed.

Although this study is limited to only patients who visited a single tertiary hospital, it is a considerable scale regarding the limited number of patients with IBD in Korea. Recently, interest and research on depression and anxiety accompanying IBD have been active, but there are still few in Korea. In particular, studies on the depression or anxiety level of patients with IBD are rare. Unlike other studies that used cutoff points to determine only the presence or absence of depression or anxiety, this study identified the size of the corresponding group according to severity. We also attempted to identify factors that should be taken more seriously when approaching and treating patients with IBD by classifying the variables that affect them according to severity. Additionally, the necessity to correct cognitive distortions along with the treatment of depression and anxiety was identified. Based on this study, cognitive evaluation should be included in clinical setting, which may be expected to provide fundamental research data for future studies. However, since it is a crosssectional study, the depression and anxiety levels according to the changes in the risk factors could not be determined. Moreover, it is possible that some risk factors may have been omitted since the mean depression and anxiety scores were not significantly high in these study participants. Perhaps the exclusion of patients with history of psychiatry clinic visit may have contributed to the low depression and anxiety scores observed in this study. To compensate for this, a screening for patients with significantly high depression and anxiety levels may be useful in identifying associated risk factors. When the risk factors were analyzed by range of scores, most of the significant risk factors were inconsistent in the subgroups by range of scores which made the results difficult to fully explain. Since this study only used self-reported scales, the objec- 
tivity of these self-reported measures may be limited. Further studies with psychiatric evaluation performed by a psychiatrist are expected to improve the objectivity of the measures.

In conclusion, psychological distress in patients with IBD requires considerable attention. Screening of patients needing treatment and research on programs to manage their psychological burden are necessary. Additional future research on the risk factors of depression or anxiety in patients with UC and CD may be helpful to both physicians and patients in the management and treatment of the disease.

\section{Acknowledgments}

This work was supported by a grant from Kyung Hee University in 2017 (KHU-20170855).

\section{Conflicts of Interest}

The authors have no potential conflicts of interest to disclose.

\section{Author Contributions}

Conceptualization: Jong Woo Kim, Won Sub Kang, Chang Kyun Lee, Hyo Jong Kim. Methodology: Jun Ho Song, Jong Woo Kim, Won Sub Kang, Chi Hyuk Oh, Chang Kyun Lee, Hyo Jong Kim. Data curation: Chi Hyuk Oh, Hyo Jong Kim, Chang Kyun Lee. Formal analysis: Jun Ho Song, Jong Woo Kim, Won Sub Kang, Chang Kyun Lee. Writing_original draft: Jun Ho Song. Writing—review \& editing: Jun Ho Song, Jong Woo Kim, Won Sub Kang, Chang Kyun Lee. Approval of final manuscript: all authors.

\section{ORCID iDs}

\section{Jun Ho Song} Jong Woo Kim Chi Hyuk Oh Hyo Jong Kim Chang Kyun Lee Won Sub Kang https://orcid.org/0000-0001-8168-3170 https://orcid.org/0000-0003-2739-8664 https://orcid.org/0000-0002-4382-5876 https://orcid.org/0000-0002-9675-4557 https://orcid.org/0000-0002-4279-3825 https://orcid.org/0000-0003-0495-2861

\section{REFERENCES}

1. Cosnes J, Gower-Rousseau C, Seksik P, Cortot A. Epidemiology and natural history of inflammatory bowel diseases. Gastroenterology 2011;140:1785-1794

2. Zhiqin W, Palaniappan S, Raja Ali RA. Inflammatory bowel diseaserelated colorectal cancer in the Asia-Pacific region: past, present, and future. Intest Res 2014;12:194-204.

3. Podolsky DK. Inflammatory bowel disease. N Engl J Med 2002;347: 417-429.

4. Kucharzik T, Maaser C, Lügering A, Kagnoff M, Mayer L, Targan S, et al. Recent understanding of IBD pathogenesis: implications for future therapies. Inflamm Bowel Dis 2006;12:1068-1083.

5. Kim HJ, Hann HJ, Hong SN, Kim KH, Ahn IM, Song JY, et al. Incidence and natural course of inflammatory bowel disease in Korea, 2006-2012: a nationwide population-based study. Inflamm Bowel Dis 2015;21:623630.

6. Lix LM, Graff LA, Walker JR, Clara I, Rawsthorne P, Rogala L, et al. Longitudinal study of quality of life and psychological functioning for active, fluctuating, and inactive disease patterns in inflammatory bowel disease. Inflamm Bowel Dis 2008;14:1575-1584.

7. Panara AJ, Yarur AJ, Rieders B, Proksell S, Deshpande AR, Abreu MT, et al. The incidence and risk factors for developing depression after being diagnosed with inflammatory bowel disease: a cohort study. Aliment Pharmacol Ther 2014;39:802-810.

8. Graff LA, Walker JR, Lix L, Clara I, Rawsthorne P, Rogala L, et al. The relationship of inflammatory bowel disease type and activity to psychological functioning and quality of life. Clin Gastroenterol Hepatol 2006;4:1491-1501.

9. Häuser W, Janke KH, Klump B, Hinz A. Anxiety and depression in patients with inflammatory bowel disease: comparisons with chronic liver disease patients and the general population. Inflamm Bowel Dis 2011;17:621-632.

10. Mikocka-Walus AA, Turnbull DA, Moulding NT, Wilson IG, Andrews JM, Holtmann GJ. Controversies surrounding the comorbidity of depression and anxiety in inflammatory bowel disease patients: a literature review. Inflamm Bowel Dis 2007;13:225-234.

11. Kovács Z, Kovács F. Depressive and anxiety symptoms, dysfunctional attitudes and social aspects in irritable bowel syndrome and inflammatory bowel disease. Int J Psychiatry Med 2007;37:245-255.

12. Walker JR, Ediger JP, Graff LA, Greenfeld JM, Clara I, Lix L, et al. The Manitoba IBD cohort study; a population-based study of the prevalence of lifetime and 12-month anxiety and mood disorders. Am J Gastroenterol 2008;103:1989-1997.

13. Nigro G, Angelini G, Grosso SB, Caula G, Sategna-Guidetti C. Psychiatric predictors of noncompliance in inflammatory bowel disease: psychiatry and compliance. J Clin Gastroenterol 2001;32:66-68.

14. Ananthakrishnan AN, Khalili H, Pan A, Higuchi LM, de Silva P, Richter JM, et al. Association between depressive symptoms and incidence of Crohn's disease and ulcerative colitis: results from the Nurses' Health Study. Clin Gastroenterol Hepatol 2013;11:57-62.

15. Goodhand JR, Wahed M, Mawdsley JE, Farmer AD, Aziz Q, Rampton DS. Mood disorders in inflammatory bowel disease: relation to diagnosis, disease activity, perceived stress, and other factors. Inflamm Bowel Dis 2012;18:2301-2309.

16. Mittermaier C, Dejaco C, Waldhoer T, Oefferlbauer-Ernst A, Miehsler $\mathrm{W}$, Beier M, et al. Impact of depressive mood on relapse in patients with inflammatory bowel disease: a prospective 18-month follow-up study. Psychosom Med 2004;66:79-84.

17. Mikocka-Walus A, Knowles SR, Keefer L, Graff L. Controversies revisited: a systematic review of the comorbidity of depression and anxiety with inflammatory bowel diseases. Inflamm Bowel Dis 2016;22:752762.

18. Larsson K, Löö L, Rönnblom A, Nordin K. Quality of life for patients with exacerbation in inflammatory bowel disease and how they cope with disease activity. J Psychosom Res 2008;64:139-148.

19. Bennebroek Evertsz F, Thijssens NA, Stokkers PC, Grootenhuis MA, Bockting CL, Nieuwkerk PT, et al. Do inflammatory bowel disease patients with anxiety and depressive symptoms receive the care they need? J Crohns Colitis 2012;6:68-76.

20. Levenstein S, Prantera C, Varvo V, Scribano ML, Berto E, Andreoli A, et al. Psychological stress and disease activity in ulcerative colitis: a multidimensional cross-sectional study. Am J Gastroenterol 1994;89:12191225.

21. von Wietersheim J, Kessler H. Psychotherapy with chronic inflammatory bowel disease patients: a review. Inflamm Bowel Dis 2006;12:11751184.

22. McCombie AM, Mulder RT, Gearry RB. Psychotherapy for inflammatory bowel disease: a review and update. J Crohns Colitis 2013;7:935949.

23. Fuller-Thomson E, Sulman J. Depression and inflammatory bowel disease: findings from two nationally representative Canadian surveys. Inflamm Bowel Dis 2006;12:697-707.

24. Lennard-Jones JE. Classification of inflammatory bowel disease. Scand J Gastroenterol Suppl 1989;170:2-6; discussion 16-19.

25. Lewis JD, Chuai S, Nessel L, Lichtenstein GR, Aberra FN, Ellenberg $\mathrm{JH}$. Use of the noninvasive components of the Mayo score to assess clinical response in ulcerative colitis. Inflamm Bowel Dis 2008;14: 1660-1666.

26. Harvey RF, Bradshaw JM. A simple index of Crohn's-disease activity. Lancet 1980;1:514. 
27. Kroenke K, Spitzer RL, Williams JB. The PHQ-9: validity of a brief depression severity measure. J Gen Intern Med 2001;16:606-613.

28. Löwe B, Gräfe K, Zipfel S, Witte S, Loerch B, Herzog W. Diagnosing ICD-10 depressive episodes: superior criterion validity of the Patient Health Questionnaire. Psychother Psychosom 2004;73:386-390.

29. Wittkampf KA, Naeije L, Schene AH, Huyser J, van Weert HC. Diagnostic accuracy of the mood module of the Patient Health Questionnaire: a systematic review. Gen Hosp Psychiatry 2007;29:388-395.

30. Gilbody S, Richards D, Barkham M. Diagnosing depression in primary care using self-completed instruments: UK validation of PHQ-9 and CORE-OM. Br J Gen Pract 2007;57:650-652.

31. Zigmond AS, Snaith RP. The hospital anxiety and depression scale. Acta Psychiatr Scand 1983;67:361-370.

32. Stern AF. The Hospital Anxiety and Depression Scale. Occup Med 2014;64:393-394.

33. Bjelland I, Dahl AA, Haug TT, Neckelmann D. The validity of the Hospital Anxiety and Depression Scale. An updated literature review. J Psychosom Res 2002;52:69-77.

34. Ganellen RJ, Matuzas W, Uhlenhuth EH, Glass R, Easton CR. Panic disorder, agoraphobia, and anxiety-relevant cognitive style. J Affect Disord 1986;11:219-225.

35. Uhlenhuth EH, McCarty T, Paine S, Warner T. The revised Anxious Thoughts and Tendencies (AT\&T) scale: a general measure of anxietyprone cognitive style. J Affect Disord 1999;52:51-58.

36. Hansson M, Chotai J, Nordstöm A, Bodlund O. Comparison of two self-rating scales to detect depression: HADS and PHQ-9. Br J Gen Pract 2009;59:e283-288.

37. Kim SJ, Hur MH. Understanding of factors influencing happiness of middle-aged women in Korea based on Maslow's hierarchy of needs. Psychiatry Investig 2019;16:539-546.

38. Park SC, Jeen YT. The mental health state of quiescent inflammatory bowel disease patients. Gut Liver 2016;10:330-331.

39. Cho OH, Yoo YS, Yang SK. [Depression and risk factors in patients with Crohn's disease]. J Korean Acad Nurs 2012;42:207-216.

40. Matsuoka K, Kobayashi T, Ueno F, Matsui T, Hirai F, Inoue N, et al. Evidence-based clinical practice guidelines for inflammatory bowel disease. J Gastroenterol 2018;53:305-353.
41. Porcelli P, Leoci C, Guerra V. A prospective study of the relationship between disease activity and psychologic distress in patients with inflammatory bowel disease. Scand J Gastroenterol 1996;31:792-796.

42. Simrén M, Axelsson J, Gillberg R, Abrahamsson H, Svedlund J, Björnsson ES. Quality of life in inflammatory bowel disease in remission: the impact of IBS-like symptoms and associated psychological factors. Am J Gastroenterol 2002;97:389-396.

43. Han SW, McColl E, Barton JR, James P, Steen IN, Welfare MR. Predictors of quality of life in ulcerative colitis: the importance of symptoms and illness representations. Inflamm Bowel Dis 2005;11:24-34.

44. Quality of life of patients with ulcerative colitis: past, present, and future. Inflamm Bowel Dis 2008;14:554-565.

45. Pierce GL, Kalil GZ, Ajibewa T, Holwerda SW, Persons J, Moser DJ, et al. Anxiety independently contributes to elevated inflammation in humans with obesity. Obesity (Silver Spring) 2017;25:286-289.

46. Ma J, Xiao L. Obesity and depression in US women: results from the 2005-2006 National Health and Nutritional Examination Survey. Obesity (Silver Spring) 2010;18:347-353 .

47. adalla TM. Association of obesity with mood and anxiety disorders in the adult general population. Chronic Dis Can 2009;30:29-36.

48. Goh J, O'Morain CA. Review article: nutrition and adult inflammatory bowel disease. Aliment Pharmacol Ther 2003;17:307-320.

49. Lewinsohn PM, Gotlib IH, Lewinsohn M, Seeley JR, Allen NB. Gender differences in anxiety disorders and anxiety symptoms in adolescents. J Abnorm Psychol 1998;107:109-117.

50. Beaulieu DB, Kane S. Inflammatory bowel disease in pregnancy. Gastroenterol Clin North Am 2011;40:399-413, ix.

51. Yang YX, Lichtenstein GR. Corticosteroids in Crohn's disease. Gastroenterol 2002;97:803-823.

52. Warrington TP, Bostwick JM. Psychiatric adverse effects of corticosteroids. Mayo Clin Proc 2006;81:1361-1367.

53. Khawaja NG, Dyer EJ. Anxious Thoughts and Tendencies Scale: an investigation of factor structure and the psychometric properties on the basis of an Australian sample. J Affect Disord 2004;79:217-221.

54. Lee SY, Kim JH, Kim YR, Gang EH, Lee DS, Yu BH. Effect of shortterm treatment of paroxetine on psychological states in panic disorder. J Korean Neuropsychiatr Assoc 2004;43:312-319. 